\title{
Growth Rates of Accessory Human Enamel: A Histological Case Study of a Modern-Day Incisor from Northern England
}

\author{
Christopher Aris $^{1 *}$ and Emma Street ${ }^{2}$ \\ ${ }_{2}^{1}$ University of Kent, Canterbury, UK \\ ${ }^{2}$ No affiliations
}

Keywords: incisor, enamel, daily secretion rates

\begin{abstract}
This study investigates enamel growth of a modern-day human upper first incisor (S197) possessing a talon cusp (accessory cusp). Growth rates collected from the accessory enamel are compared to data collected from the primary cusp and cusps of a standard incisor sample from the same population. Upper first incisors $(n=12)$ and S197 were analysed using histological methods. Daily secretion rates (DSRs) were calculated for inner, mid, and outer regions of cuspal and lateral sites. Additional DSRs were calculated for equivalent regions of S197's accessory cusp. S197's primary cusp DSRs were significantly faster than the accessory cusp for all lateral regions, but significantly slower in the inner and mid cuspal regions. S197's primary cusp DSRs were also significantly slower than the standard incisor sample for all regions except the lateral cuspal. The DSRs of the standard sample were significantly faster than those of S197's accessory cusp for all lateral regions, but significantly slower in the inner cuspal region. This case study displays that human teeth possessing accessory cusps can present varying DSRs to teeth lacking accessory enamel from the same population, and that accessory enamel growth may not follow the same pattern of increasing DSRs along the length of enamel prisms.
\end{abstract}

The study of modern human enamel growth rates via histological analysis is common within the study of biological anthropology and bioarchaeology, commonly focusing on the variation between cusps of the same tooth (e.g. Mahoney, 2008), within single populations (e.g. Schwartz et al., 2001), and between populations (e.g. Smith et al., 2007; Aris et al., 2020a, 2020b). A common trend between these lines of research is the exclusive use of what are deemed as dental samples containing no evidence of pathology, stress markers, or growth of accessory enamel (defined here as: growth of enamel outside of the features typically used to define and identify human tooth types). While past research has touched on how some human enamel growth features vary between individuals suffering from stress and those not suffering from stress resulting in dental morphologies, these typically concern the accuracy of making certain calculations relating to enamel growth (Lukacs \& Guatelli -Steinberg, 1994; Guatelli-Steinberg \& Lukacs, 1999), and the development of non-accessory enamel (defined here as: growth of the enamel features which define how human tooth types are identified and classified) in individuals presenting evidence of stress on their dental morphology (e.g. Fitzgerald \& Saunders, 2005). Comparison of enamel growth rates collected from teeth presenting accessory enamel to those with no evidence of stress markers or non-metric traits from the same population, and comparison of accessory enamel growth to the growth of non-accessory enamel within the same tooth, have yet to be conducted. This project aims to begin to address these issues and widen our understanding of accessory enamel growth in modern-day humans through the case study of a modern-day upper first incisor.

\section{Background}

Amelogenesis and daily enamel growth

Amelogenesis is the process of secretion and mineralization of protein matrix by ameloblast cells (Boyde, 1989; Nanci \& Smith, 1992; Smith \& Nanci, 1995). During the secretory stage of amelogenesis,

${ }^{*}$ Correspondence to:

Christopher Aris

Department of Archaeology

Ella Armitage Building

University of Sheffield

Sheffield, UK

c.aris@sheffield.ac.uk 
ameloblast secretion is altered according to a daily circadian rhythm, producing short-period markers along the length of enamel prisms (e.g., Asper, 1916; Gysi, 1931; Massler \& Schour, 1946; Okada, 1943; Kajiyama, 1965; Dean et al., 1993; Smith \& Nanci, 2003). These daily forming markers are known as cross striations (e.g. Boyde, 1963; 1990; Kajiyama, 1965; Bromage, 1991; Dean, 1995; Fitzgerald, 1995, 1998; Antoine, 2000; Antoine et al., 2009). The formation of cross striations causes alterations in the refractive index of enamel prisms, making them observable in thin sections under transmitted light (e.g. Berkovitz et al., 2002; Zheng et al., 2013).

Daily secretion rates (DSRs) can be calculated from cross striations. These rates accelerate from inner enamel regions proximal to the enamel dentine junction towards the outer enamel surface (e.g. Beynon et al., 1991 Beynon et al., 1998; Reid et al., 1998; Lacruz \& Bromage, 2006; Mahoney, 2008; Aris et al., 2020a, 2020b). Daily secretion rates are also faster relative to their proximity to the dentine horn (Beynon et al., 1991). Due to DSRs varying within a tooth, analysis of these rates are undertaken for specific regions (e.g. Dean, 1998) where the crown is divided into cuspal, lateral, and cervical enamel, and then further subdivided into inner, mid, and outer regions. Typically, DSRs are broadly similar when equivalent regions are compared between cusps within a molar (Mahoney, 2008).

Analysis of DSRs for human samples have examined variations within individual teeth (Mahoney, 2008), differences between biologically male and female groups (Schwartz et al., 2001), and more recently variations between populations (Aris et al., 2020a, 2020b). Despite the breadth of these studies, they have universally used teeth absent of evidence of stress, pathology, and accessory enamel growth. Thus, our understanding of how human DSRs vary in accessory enamel in comparison to non-accessory enamel is limited.

\section{Enamel growth patterns within pathological cases}

While the DSRs of accessory enamel have not yet been analysed, certain features of enamel growth have been analysed for individuals presenting signs of stress on their dentition. These studies have focused on the possible changes in amelogenesis, which leads to the formation of enamel growth defects observable from internal and external analysis. Lukacs and colleagues have published a series of papers explaining the pattern and expression of enamel defects in modern humans. These can vary due to diet, geographic location, and climate. In particular, these papers present evidence of longer crown formation times (CFTs) in stressed individuals (Lukacs et al., 1989; Lukacs, 1991, 1992, 1999; Lukacs \& Joshi, 1992; Lukacs \& Pal, 1993; Lukacs \& Guatelli-Steinberg, 1994; Luckas \& Walimbe, 1998; Guatelli-Steinberg \& Lukacs, 1999). As CFTs are directly related to the products of daily enamel growth (e.g. Massler \& Schour, 1946) there is potential that accessory enamel possesses growth rates which vary from non-accessory enamel.

Fitzgerald and Saunders (2005) investigated the possibility of using enamel defects to predict the age at which stress was incurred and thus improve the way in which we interpret the influence of stress on enamel growth patterns. This concept was based on the ability to age through examining interior enamel structures, and that these structures would be notably altered during stressful events. Through the use of a large sample size (274 teeth from 127 Roman subadults), they concluded that enamel formation patterns are more highly impacted according to the severity of the cause of stress, and that there is no minimum requirement of stress level for enamel to be effected (Fitzgerald \& Saunders, 2005). Multiple papers have since been published on this topic, all conclusively stating that stress impacts enamel structures, significantly increases CFTs, and reduces the reliability of DSR calculations (Reid \& Dean, 2006; Holt et al., 2012; Birch \& Dean, 2014; Primeau et al., 2015). As a result of these studies, we can reliably say that nonaccessory enamel grows differentially in individuals presenting evidence of stress. It is therefore important to expand our understanding of how accessory enamel grows in relation to non-accessory enamel.

\section{Material and methods \\ Dental sample}

Upper permanent first incisors $(n=13)$ were selected from a modern-day collection consisting of teeth extracted between 1964 and 1973 at dental surgeries in northern England and southern Scotland. All 13 samples originated from NewcastleUpon-Tyne, including an incisor presenting an accessory enamel cusp (S197). The accessory cusp of S197 has developed on the cingulum and reached beyond half the distance to the incisal edge (Figure 1 ), as such it is diagnosed as a talon cusp (Edgar et al., 2016). The remaining 12 incisors made up a standard sample, with each tooth presenting no evidence of stress, pathology, or accessory enamel growth. Right teeth were selected unless it was 
unavailable or the left was better preserved. The collection itself is curated at the Skeletal Biology Research Centre, University of Kent, as part of the UCL/Kent Collection. Ethical approval for the histological analysis of this dental sample was obtained from the UK National Health Service research ethics committee (REC reference: 16/ SC/0166; project ID: 203541).

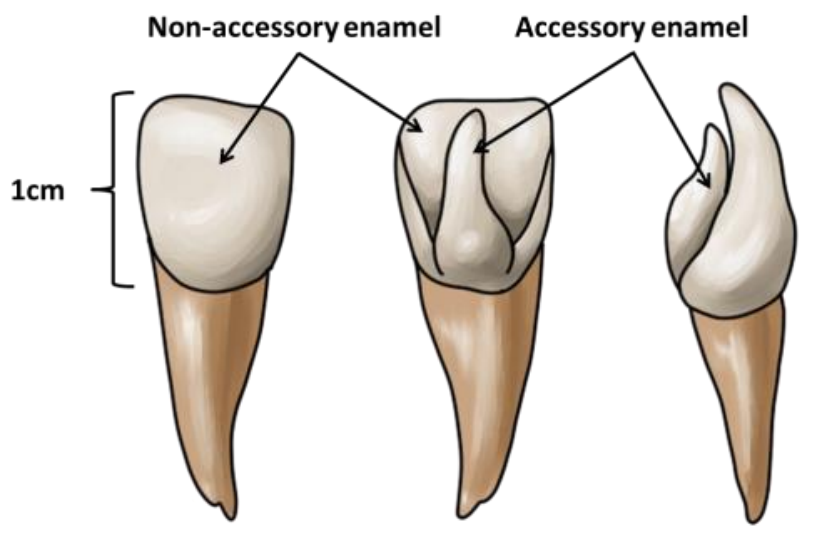

Figure 1. Depictions of upper first permanent incisor S197 prior to sectioning highlighting the regions defined as accessory and non-accessory enamel. Moving left to right the images display the tooth from the labial, lingual, and mesial directions.

\section{Sample preparation}

Resin casts were produced for each incisor prior to any destructive analysis, and were produced using standard methods (Aris, 2020). The casts reproduced the surface morphology of the tooth crown allowing for future study of microwear, crown morphology, and enamel surface features including linear enamel hypoplasia and perikymata.

Thin sections were produced using standard histological procedures (e.g. Schwartz et al., 2005; Mahoney, 2008; Aris, 2020). The incisors were embedded in an epoxy resin and hardener mixture (Buehler ${ }^{\circledR}$ ) to minimise the chance of the teeth fracturing during sectioning. Embedded samples were then cut at a low speed using a diamond-edged wafering blade (Buehler ${ }^{\circledR}$ IsoMet 1000 Precision Cutter) at a longitudinal angle through the apex of the incisal crowns. The samples were then mounted on glass microscope slides and lapped using progressively finer grinding pads (Buehler ${ }^{\circledR}$ ) until around $120 \mu \mathrm{m}$ in thickness. Ground samples were polished using $0.3 \mu \mathrm{m}$ aluminium oxide powder until evidence of lapping was removed from the mounted dental samples. Polished samples were then placed within an ultrasonic bath for two minutes in order to remove any remaining debris before being dehydrated using $90 \%$ and $100 \%$ ethanol-based solutions (Fisher scientific ${ }^{\circledR}$ ). The dehydrated sections were finally cleared using Histocle$a^{\circledR}$ and mounted with a glass cover slip using a mounting medium (DPX®). All sections were examined using polarised light microscopy (Olympus BX53 Upright Microscope). Analysis and image capture was conducted using micro imaging software (cellSens) (see below for detail).

\section{Daily secretion rates}

The DSRs for the incisors were calculated for the inner, mid, and outer areas of the lateral and cuspal enamel sites of each tooth using standard methods (e.g. Beynon et al., 1991a; Schwartz et al., 2001; Mahoney, 2008; Aris et al., 2020a, 2020b). Each region within the cuspal and lateral sites was determined by dividing the length of the enamel regions into three equidistant portions, following the longitudinal axis of local enamel prisms (Figure 2). The lateral enamel areas were determined within the section of imbricational enamel equidistant between the dental cervix and dentine horn. Regions of cuspal enamel were determined within the appositional enamel starting near the dentine horn. Additional DSRs were calculated for isolated regions of S197's accessory cusp (see Figure 2). These regions were selected in a fashion as to mirror the cuspal and lateral regions of the primary cusp.

Within each enamel region a measurement was made of five consecutive cross striations along the length of an enamel prism. This measurement was subsequently divided by five, giving a mean daily rate of matrix secretion ( $\mu \mathrm{m} /$ day). This process was repeated to produce six mean DSRs for each region. For the standard incisor sample these results were then similarly divided to give a grand mean and standard deviation, following the standard statistical and methodological approaches of studying human enamel growth rates (e.g. Beynon et al., 1991 Beynon et al., 1998; Reid et al., 1998; Lacruz \& Bromage, 2006; Mahoney, 2008; Aris et al., 2020a, 2020b). For S197 the six mean DSRs for each region were kept separate for future analysis. All cross striation measurements were taken between 20x and 40x magnification (Figure 3).

\section{Statistical analysis}

Independent sample T-tests were used to compare mean equivalent regional DSRs between the selected samples. First, the same DSRs of the primary cusp and accessory cusp of S197 were compared. 


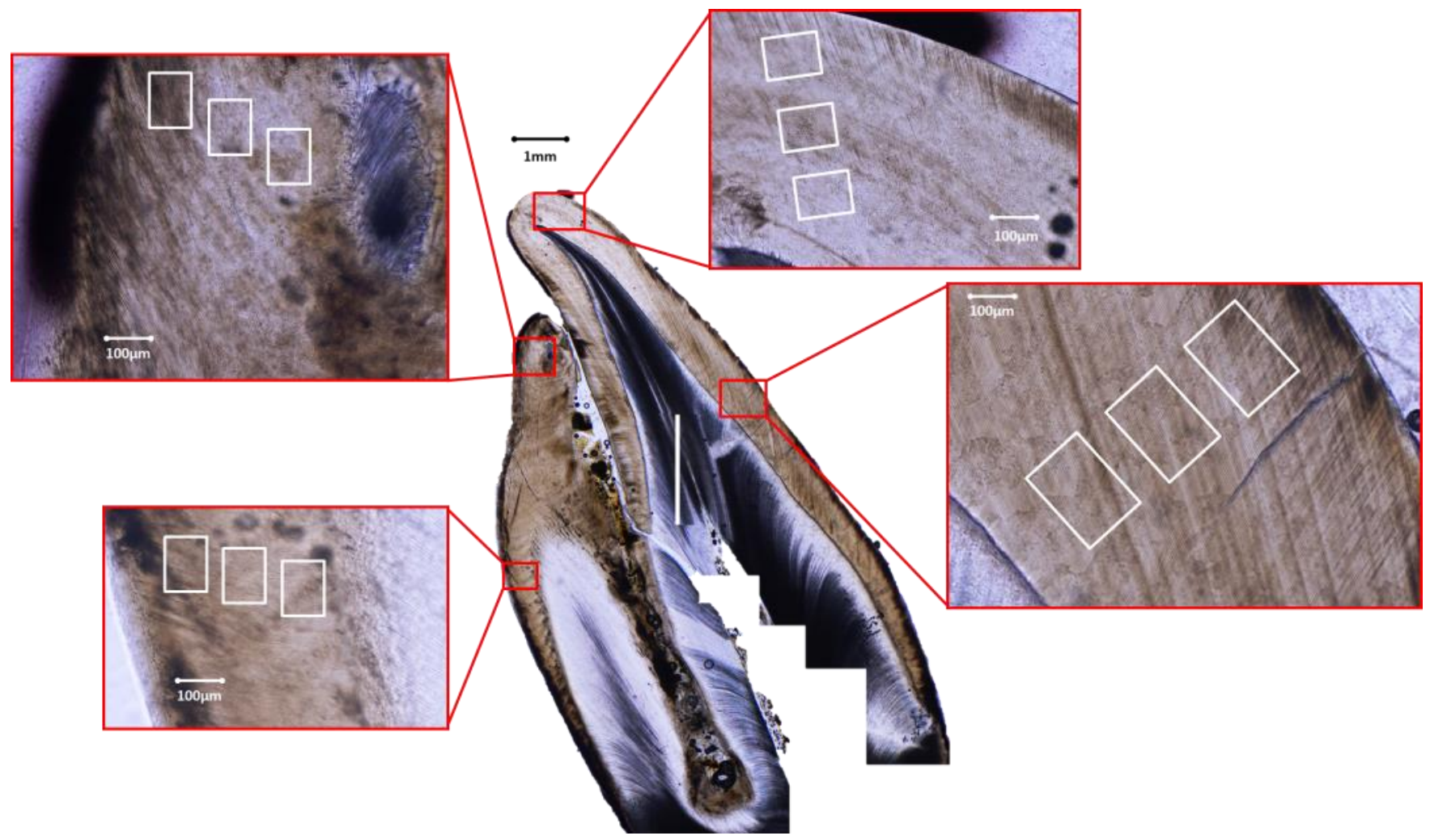

Figure 2. Cross section of Sample 197 displaying the regions from which DSRs were collected. Right superimpositions show the cuspal (top) and lateral (bottom) sites of the primary cusp. Left superimpositions show the cuspal (top) and lateral (bottom) sites of the accessory enamel. White squares represent the inner, mid, and outer regions of each site respectively moving from the enamel dentine junction towards the outer enamel surface. Daily secretion rates were collected from healthy clinical teeth from equivalent cuspal and lateral sites to the right superimpositions.

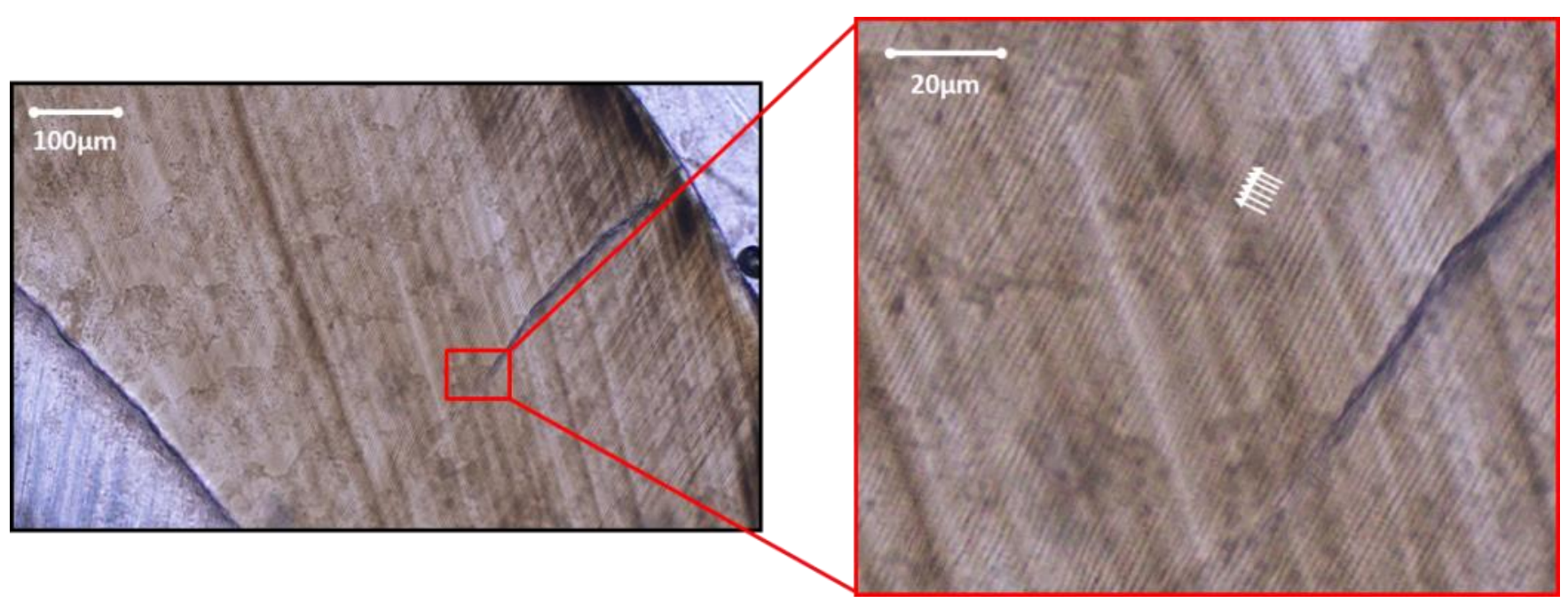

Figure 3. Cross section of the cuspal enamel site of the primary cusp of Sample 197. The right superimposition displays a portion of the mid cuspal region, and the white arrows indicate individual cross striations. 
Second, the DSRs collected from the primary cusp mean rate of $0.27 \mu \mathrm{m} /$ day $(p=0.01)$ in the inner reenamel of S197 were compared to those of the gion, $0.51 \mu \mathrm{m} /$ day $(p<0.00)$ in the mid region, and standard clinical sample. Third, the DSRs of the $0.37 \mu \mathrm{m} /$ day $(p=0.02)$ in the outer region. The accessory enamel of S197 were compared to those standard sample also presented significantly faster of the standard clinical sample. All statistical anal- DSRs for the inner and mid cuspal enamel regions. yses were conducted using SPSS 24.0.

\section{Results}

Accessory enamel DSRs compared to primary cusp DSRS

These were faster by a mean rate of $0.69 \mu \mathrm{m} /$ day $(p<0.00)$ in the inner region, and $0.65 \mu \mathrm{m} /$ day $(p<0.00)$ in the mid region.

Table 1 displays the results of comparing the mean DSRs of the primary cusp enamel to those of the accessory cusp enamel, all collected from S197. For the inner and mid regions of the lateral enamel the primary cusp enamel presented significantly faster DSRs. These were faster by a mean rate of $0.53 \mu \mathrm{m} /$ day $(p<0.00)$ in the inner region, and $0.47 \mu \mathrm{m} /$ day $(p=0.01)$ in the mid region. Conversely, accessory enamel presented significantly faster DSRs for the inner and mid cuspal enamel regions. These were faster by a mean rate of $2.14 \mu \mathrm{m} /$ day $(p<0.00)$ in the inner region, and $1.02 \mu \mathrm{m} /$ day $(p<0.00)$ in the mid region.

Accessory enamel DSRs compared to rest of population

Table 3 displays the results of comparing the mean DSRs of the accessory enamel of S197 to those of the standard clinical sample. For all regions of the lateral enamel, the standard sample presented significantly faster DSRs. These were faster by a mean rate of $0.80 \mu \mathrm{m} /$ day $(p<0.00)$ in the inner region, $0.98 \mu \mathrm{m} /$ day $(p<0.00)$ in the mid region, and $0.59 \mu \mathrm{m} /$ day $(p<0.00)$ in the outer region. Converse$1 \mathrm{y}$, the accessory enamel sample presented significantly faster DSRs for the inner cuspal enamel region by a mean rate of $1.45 \mu \mathrm{m} /$ day $(p<0.00)$.

\section{Discussion}

Inter-regional enamel growth of S197

Non-accessory enamel DSRs compared to rest of population

The lateral enamel DSRs of the primary cusp were significantly faster than those of the accessory Table 2 displays the results of comparing the mean enamel in the inner and mid regions. Conversely, DSRs of the primary cusp enamel of S197 to those the accessory enamel cuspal DSRs were significantof the standard clinical sample. For all regions of ly faster than those of the primary cusp for the inthe lateral enamel, the standard sample presented ner and mid regions (see Table 1). This finding significantly faster DSRs. These were faster by a goes against those of past research, which found

Table 1. Results of the independent samples T-tests comparing the mean regional DSRs ( $\mu \mathrm{m} /$ day) of the accessory enamel of Sample 197 to the primary cusp enamel of Sample 197. Significant results are marked in bold, ${ }^{*} p<0.00$.

\begin{tabular}{llllllll}
\hline Enamel Region & Sample & $\mathrm{N}$ & Mean & Min & Max & S.D. & Sig. \\
\hline & & Lateral Enamel & & & & \\
\hline Inner & Accessory & 6 & 2.24 & 2.02 & 2.37 & 0.14 & $\mathbf{0 . 0 0}^{*}$ \\
& Primary cusp & 6 & 2.77 & 2.48 & 2.98 & 0.19 & \\
\hline Mid & Accessory & 6 & 2.51 & 2.37 & 2.81 & 0.16 & $\mathbf{0 . 0 1}$ \\
& Primary cusp & 6 & 2.98 & 2.67 & 3.35 & 0.24 & \\
\hline Outer & Accessory & 6 & 3.13 & 2.89 & 3.78 & 0.33 & 0.42 \\
& Primary cusp & 6 & 3.35 & 2.88 & 3.77 & 0.34 & \\
\hline \multirow{2}{*}{ Inner } & Cuspal Enamel & & & & \\
& Accessory & 6 & 4.65 & 4.30 & 4.98 & 0.21 & $\mathbf{0 . 0 0 ^ { * }}$ \\
\hline Mid & Primary cusp & 6 & 2.51 & 2.14 & 2.78 & 0.12 & \\
\hline Outer & Accessory & 6 & 3.91 & 3.37 & 4.41 & 0.37 & $\mathbf{0 . 0 0 *}$ \\
& Primary cusp & 6 & 2.89 & 3.44 & 2.40 & 0.25 & \\
\hline
\end{tabular}


Table 2. Results of the independent samples T-tests comparing the mean regional DSRs ( $\mu$ m/day) of the healthy samples to those collected from the primary cusp enamel of Sample 197. Significant results are marked in bold, ${ }^{*} p<0.00$.

\begin{tabular}{llllllll}
\hline Enamel Region & Sample & $\mathrm{N}$ & Mean & Min & Max & S.D & Sig. \\
\hline Inner & & Lateral Enamel & & & & \\
& Primary cusp & 6 & 2.77 & 2.48 & 2.98 & 0.19 & $\mathbf{0 . 0 1}$ \\
& Healthy & 12 & 3.04 & 2.56 & 3.32 & 0.21 & \\
\hline Mid & Primary cusp & 6 & 2.98 & 2.67 & 3.35 & 0.24 & $\mathbf{0 . 0 0}^{*}$ \\
& Healthy & 12 & 3.49 & 2.86 & 3.80 & 0.27 & \\
\hline Outer & Primary cusp & 6 & 3.35 & 2.88 & 3.77 & 0.34 & $\mathbf{0 . 0 2}$ \\
& Healthy & 12 & 3.72 & 3.14 & 4.06 & 0.25 & \\
\hline Inner & & Cuspal Enamel & & & & \\
\hline Mid & Primary cusp & 6 & 2.51 & 2.14 & 2.78 & 0.12 & $\mathbf{0 . 0 0}$ \\
& Healthy & 8 & 3.20 & 2.84 & 3.43 & 0.23 & \\
\hline Outer & Primary cusp & 6 & 2.89 & 3.44 & 2.40 & 0.25 & $\mathbf{0 . 0 0 *}$ \\
& Healthy & 8 & 3.54 & 3.16 & 3.86 & 0.22 & \\
\hline
\end{tabular}

Table 3. Results of the independent samples T-tests comparing the mean regional DSRs ( $\mu \mathrm{m} /$ day) of the healthy samples to those collected from the accessory enamel of Sample 197. Significant results are marked in bold, ${ }^{*} p<0.00$.

\begin{tabular}{|c|c|c|c|c|c|c|c|}
\hline Enamel Region & Sample & $\mathrm{N}$ & Mean & Min & Max & S.D & Sig. \\
\hline \multicolumn{8}{|c|}{ Lateral Enamel } \\
\hline \multirow[t]{2}{*}{ Inner } & Accessory & 6 & 2.24 & 2.02 & 2.37 & 0.14 & $0.00^{*}$ \\
\hline & Healthy & 12 & 3.04 & 2.56 & 3.32 & 0.21 & \\
\hline \multirow[t]{2}{*}{ Mid } & Accessory & 6 & 2.51 & 2.37 & 2.81 & 0.16 & $0.00^{*}$ \\
\hline & Healthy & 12 & 3.49 & 2.86 & 3.80 & 0.27 & \\
\hline \multirow[t]{2}{*}{ Outer } & Accessory & 6 & 3.13 & 2.89 & 3.78 & 0.33 & $0.00^{*}$ \\
\hline & Healthy & 12 & 3.72 & 3.14 & 4.06 & 0.25 & \\
\hline \multicolumn{8}{|c|}{ Cuspal Enamel } \\
\hline \multirow[t]{2}{*}{ Inner } & Accessory & 6 & 4.65 & 4.30 & 4.98 & 0.21 & $0.00^{*}$ \\
\hline & Healthy & 8 & 3.20 & 2.84 & 3.43 & 0.23 & \\
\hline \multirow[t]{2}{*}{ Mid } & Accessory & 6 & 3.91 & 3.37 & 4.41 & 0.37 & 0.05 \\
\hline & Healthy & 8 & 3.54 & 3.16 & 3.86 & 0.22 & \\
\hline \multirow[t]{2}{*}{ Outer } & Accessory & 6 & 3.71 & 3.09 & 4.14 & 0.46 & 0.74 \\
\hline & Healthy & 8 & 3.89 & 3.36 & 4.09 & 0.23 & \\
\hline
\end{tabular}


DSRs to remain similar between equivalent regions of different non-accessory cusps in typically multicusped teeth (Mahoney, 2008). This unusual variation in DSR differences between the cusps is the product of the cuspal DSRs of the accessory cusp slowing with distance from the enamel dentine junction (EDJ) along the enamel prism pathway. This trend also differs to that seen in past research, which has shown permanent enamel growth rates of non-accessory enamel to always accelerate with distance from the EDJ (e.g. Beynon et al., 1991, 1998; Reid et al., 1998; Lacruz \& Bromage, 2006; Mahoney, 2008; Aris et al., 2020a, 2020b).

This finding, in particular, demands further investigation, primarily to identify if the reversed growth pattern in cuspal DSRs of accessory enamel growth is consistent in other human samples. Should this be the case then the expected principle notion of enamel growth rates increasing with distance, a principle formulated on teeth not presenting accessory enamel growth from the EDJ, would need to be addressed. It is plausible that this principle, highly supported by the data of past research (e.g. Beynon et al., 1991; Beynon et al., 1998; Reid et al., 1998; Lacruz \& Bromage, 2006; Mahoney, 2008; Aris et al., 2020a, 2020b) can only accurately be applied to growth of non-accessory enamel. Further research on the growth rates of accessory enamel is therefore required in order to create an equivalent growth principle for non-accessory enamel.

Primary cusp enamel growth compared to standard sample

Despite being the primary cusp of S197 and displaying standard morphology for an upper permanent first incisor, the regional enamel DSRs varied significantly from the mean DSRs of the standard sample (Table 2). Mean DSRs of all lateral enamel regions, and the inner and mid cuspal regions, were significantly slower in S197. However, outer cuspal DSRs were slower by only a mean rate of $0.05 \mu \mathrm{m} /$ day in S197. Overall, while this research only presents a preliminary case study, the data suggests that such enamel will grow slower than the standard sample cohort of the same tooth type within the same population.

This finding primarily supports the use of teeth possessing no abnormal or excess enamel in past growth rate studies (e.g. Beynon et al., 1991; Beynon et al., 1998; Reid et al., 1998; Lacruz \& Bromage, 2006; Mahoney, 2008; Aris et al., 2020a, $2020 b$ ), as there is now clear potential for significant differences between teeth that do and do not present accessory enamel growth as defined here. Perhaps more importantly, there is new incentive for future research to continue analysing the growth rates throughout all regions and types of enamel from all tooth types. Such research will serve to expand our knowledge of the growth rate patterns common in human dentition, by identifying if non-accessory enamel growth rates slow in the presence of accessory enamel on the same tooth, or if S197 is a unique case. Future research should also examine the growth rates of less extreme non-accessory enamel growth than that of S197. This would help ascertain whether the extremity of accessory enamel growth is related to the slowing growth rates of the non-accessory enamel.

Accessory cusp enamel growth compared to standard sample

The lateral enamel DSRs of the accessory cusp of S197 presented significantly slower rates compared to those of the standard sample (Table 3). Conversely, the inner cuspal DSRs of the accessory cusp were significantly faster. The mid cuspal region was also faster by a mean rate of $0.37 \mu \mathrm{m} /$ day, but the outer cuspal region presented minimal variation to the standard sample (Table 3). These results demonstrate the erratic and inconsistent growth patterns of the accessory enamel of S197. It is particularly unusual that the cuspal accessory enamel growth slowed from inner to outer regions, and that the outer region mean DSR climaxed at a similar rate to equivalent DSRs of the standard sample. Further research is required to ascertain whether this is a unique phenomenon or the standard growth pattern for accessory enamel.

However, it should be noted that accessory enamel manifestations differ between different dental non-metric traits whose etiology includes excess enamel formation. Future research investigating the growth of accessory enamel should therefore consider analysing growth rates of teeth grouped according to their diagnosed traits and tooth types, as it should not be assumed that accessory enamel grows at similar rates between these groups. This principle should be applied to all future research advised here to avoid inaccurately grouping the growth patterns of all non-accessory enamel types.

\section{Conclusions}

The inter-regional differences in the growth rates collected from S197 were erratic, and in some enamel regions in direct contradiction with those expected of human incisors and multi-cusped teeth. Firstly, the differences between the equivalent regional DSRs of the primary and secondary 
cusp of S197 vary from the similarities observed in past research comparing non-accessory cusps of the same teeth. Secondly, the presence of extreme accessory enamel formation appeared to slow the growth rates of the non-accessory enamel when compared to the growth rates of a standard sample of teeth lacking accessory enamel growth. Finally, the DSRs from the accessory cusp of S197 highlight how accessory enamel growth rates will not necessarily follow the trend of increasing rates with distance from the EDJ. The lack of additional research greatly limits our understanding of these findings. Overall, it is clear that more research into the growth rates of accessory enamel, as well as nonaccessory enamel of the same teeth, is needed. Ideally such research will analyse different tooth types, and teeth with different diagnosed nonmetric traits, independently.

\section{Acknowledgments}

We would like to thank the University of Kent for granting permission to sample teeth from their clinical collection. Further thanks also go to Annie Robertson for her assistance and artistic talents. Thanks also go to the anonymous reviewer and editor for their invaluable feedback.

\section{REFERENCES}

Antoine, D. (2000). Evaluating the periodicity of incremental structures in dental enamel as a means of studying growth in children from past human populations (Doctoral dissertation, University College London).

Antoine, D., Hillson, S., \& Dean, M. C. (2009). The developmental clock of dental enamel: a test for the periodicity of prism cross-striations in modern humans and an evaluation of the most likely sources of error in histological studies of this kind. Journal of Anatomy, 214(1), 45-55.

Aris, C. (2020). The Histological Paradox: Methodology and efficacy of dental sectioning. Papers from the Institute of Archaeology, 29(1), 1-16.

Aris, C., Mahoney, P., \& Deter, C. (2020a). Enamel thickness and growth rates in modern human permanent first molars over a 2000 year period in Britain. American Journal of Physical Anthropology, 173, 141-157.

Aris, C., Mahoney, P., O'Hara, M. C., \& Deter, C. (2020b). Enamel growth rates of anterior teeth in males and females from modern and ancient British populations. American Journal of Physical Anthropology, 173, 236-249.

Asper, H. (1916). Uber die "braune Retzius'sche Parallelsteifung" im Schmelz der menschlichen Zahne. Schweiz Vjschr. Zahnhlk, 26(1), 275-314
Berkovitz, B. K. B., Holland, G. R., \& Moxham, B. J. (2002). Oral anatomy, embryology and histology. Mosby Incorporated.

Beynon, A. D., Clayton, C. B., Ramirez Rozzi, F. V. R., \& Reid, D. J. (1998). Radiographic and histological methodologies in estimating the chronology of crown development in modern humans and great apes: a review, with some applications for studies on juvenile hominids. Journal of Human Evolution, 35(4), 351-370.

Beynon, A. D., Dean, M. C., \& Reid, D. J. (1991). Histological study on the chronology of the developing dentition in gorilla and orangutan. American Journal of Physical Anthropology, 86(2), 189-203.

Birch, W., \& Dean, M. C. (2014). A method of calculating human deciduous crown formation times and of estimating the chronological ages of stressful events occurring during deciduous enamel formation. Journal of Forensic and Legal Medicine, 22, 127-144.

Boyde, A. (1989). Enamel. In Teeth (pp. 309-473). Springer, Berlin, Heidelberg.

Boyde, A., (1990). Developmental interpretations of dental microstructure. In DeRousseau, J.C. (Ed.), Primate Life History and Evolution (pp. 229 -267). New York: Wiley-Liss.

Boyde, A. (1990). Developmental interpretations of dental microstructure. In DeRousseau, J.C. (Ed.), Primate Life History and Evolution (pp. 229 -267). New York: Wiley-Liss.

Bromage, T. G. (1991). Enamel incremental periodicity in the pig-tailed macaque: A polychrome fluorescent labeling study of dental hard tissues. American Journal of Physical Anthropolo$g y, 86(2), 205-214$.

Dean, M. C. (1995). The nature and periodicity of incremental lines in primate dentine and their relationship to periradicular bands in $\mathrm{OH} 16$ (Homo habilis). In J. M. Cecchi (Ed.), Aspects of dental biology: Paleontology, anthropology and evolution (pp. 239-265). Florence: International Institute for the Study of Man.

Dean, M. C. (1998). A comparative study of cross striation spacings in cuspal enamel and of four methods of estimating the time taken to grow molar cuspal enamel in Pan, Pongo and Homo. Journal of Human Evolution, 35(4), 449-462.

Dean, M. C., Beynon, A. D., Reid, D. J., \& Whittaker, D. K. (1993a). A longitudinal study of tooth growth in a single individual based on long-and short-period incremental markings in dentine and enamel. International Journal of Osteoarchaeology, 3(4), 249-264.

Edgar, H. J. H., Willermet, C., Ragsdale, C. S., 
O'Donnell, A., \& Daneshvari, S. (2016). Frequencies of rare incisor variations reflect factors influencing precontact population relationships in Mexico and the American Southwest. International Journal of Osteoarchaeology, 26 (6), 987-1000.

FitzGerald, C. M. (1995). Tooth crown formation and the variation of enamel microstructural growth markers in modern humans (Doctoral dissertation, University of Cambridge).

FitzGerald, C. M. (1998). Do enamel microstructures have regular time dependency? Conclusions from the literature and a large-scale study. Journal of Human Evolution, 35(4-5), 371386.

FitzGerald, C. M., \& Saunders, S. R. (2005). Test of histological methods of determining chronology of accentuated striae in deciduous teeth. American Journal of Physical Anthropolo$g y, 127(3), 277-290$.

Guatelli-Steinberg, D., \& Lukacs, J. R. (1999). Interpreting sex differences in enamel hypoplasia in human and non-human primates: Developmental, environmental, and cultural considerations. American Journal of Physical Anthropolo$g y$, 110(S29), 73-126.

Gysi, A. (1931). Metabolism in adult enamel. Dental Dig, 37, 661-668

Holt, S. A., Reid, D. J., \& Guatelli-Steinberg, D. (2012). Brief communication: premolar enamel formation: completion of figures for aging LEH defects in permanent dentition. Dental Anthropology Journal, 25(1), 4-7.

Kajiyama, S. (1965). Total number of regular incremental lines (Regulare Parallelstreifen nach Asper) in the enamel of human permanent teeth. Journal of Nihon University School of Dentistry, 39, 77-83.

Lukacs, J. R. (1991). Localized enamel hypoplasia of human deciduous canine teeth: prevalence and pattern of expression in rural Pakistan. Human Biology, 63(4), 513-522.

Lukacs, J. R. (1992). Dental paleopathology and agricultural intensification in South Asia: new evidence from Bronze Age Harappa. American Journal of Physical Anthropology, 87(2), 133-150.

Lukacs, J. R. (1999). Enamel hypoplasia in deciduous teeth of great apes: Do differences in defect prevalence imply differential levels of physiological stress?. American Journal of Physical Anthropology, 110(3), 351-363.

Lacruz, R. S., \& Bromage, T. G. (2006). Appositional enamel growth in molars of South African fossil hominids. Journal of Anatomy, 209(1), 1320.

Lukacs, J. R., \& Guatelli-Steinberg, D. (1994). Daughter neglect in India: LEH prevalence and the question of female biological superiority. American Journal of Physical Anthropology, Supplement, 18, 132.

Lukacs, J. R., \& Joshi, M. R. (1992). Enamel hypoplasia prevalence in three ethnic groups of northwest India: A test of daughter neglect and a framework for the past. Recent contributions to the study of enamel developmental defects. Journal of Paleopathology Monograms Publications, 2, 359-372.

Lukacs, J. R., \& Pal, J. N. (1993). Mesolithic subsistence in North India: inferences from dental attributes. Current Anthropology, 34(5), 745-765.

Lukacs, J. R., \& Walimbe, S. R. (1998). Physiological stress in prehistoric India: new data on localized hypoplasia of primary canines linked to climate and subsistence change. Journal of Archaeological Science, 25(6), 571-585.

Mahoney, P. (2008). Intraspecific variation in M1 enamel development in modern humans: implications for human evolution. Journal of $\mathrm{Hu}$ man Evolution, 55(1), 131-147.

Massler, M., \& Schour, I. (1946). Growth of the child and the calcification pattern of the teeth. American Journal of Orthodontics and Oral Surgery, 32(9), 495-517.

Nanci, A. and Smith. C. E. (1992). Development and calcification of enamel. In E. Bonucci, (Ed.) Calcification in Biological Systems (pp 313-343). Boca Raton, FL: CRC Press.

Okada, M. (1943). Hard tissues of animal body. Highly interesting details of Nippon studies in periodic patterns of hard tissues are described. Shanghai Evening Post. Medical Edition of September 1943, 15-31.

Primeau, C., Arge, S. O., Boyer, C., \& Lynnerup, N. (2015). A test of inter-and intra-observer error for an atlas method of combined histological data for the evaluation of enamel hypoplasia. Journal of Archaeological Science: Reports, 2, 384-388.

Reid, D. J., Beynon, A. D., \& Ramirez Rozzi, F. V. R. (1998). Histological reconstruction of dental development in four individuals from a medieval site in Picardie, France. Journal of Human Evolution, 35(4-5), 463-477.

Reid, D. J., \& Dean, M. C. (2006). Variation in modern human enamel formation times. Journal of Human Evolution, 50(3), 329-346. 
Schwartz, G. T., Mahoney, P., Godfrey, L. R., Cuozzo, F. P., Jungers, W. L., \& Randria, G. F. (2005). Dental development in Megaladapis edwardsi (Primates, Lemuriformes): implications for understanding life history variation in subfossil lemurs. Journal of Human Evolution, 49 (6), 702-721.

Schwartz, G. T., Reid, D. J., \& Dean, C. (2001). Developmental aspects of sexual dimorphism in hominoid canines. International Journal of Primatology, 22(5), 837-860.

Smith, C. E., \& Nanci, A. (2003). Overview of morphological changes in enamel organ cells associated with major events in amelogenesis. International Journal of Developmental Biology, 39(1), 153-161.

Smith, T. M., Reid, D. J., Dean, M. C., Olejniczak, A. J., \& Martin, L. B. (2007). New perspectives on chimpanzee and human molar crown development. In: Dental perspectives on human evolution: state of the art research in dental paleoanthropology. Springer, Dordrecht. pp. 177-192.

Zheng, J., Li, Y., Shi, M. Y., Zhang, Y. F., Qian, L. M., \& Zhou, Z. R. (2013). Microtribological behaviour of human tooth enamel and artificial hydroxyapatite. Tribology International, 63, 177185. 